\title{
In-kind transfers, self-selection and optimal tax policy
}

\author{
Helmuth Cremer \\ IDEI and GREMAQ, University of Toulouse \\ Toulouse, France \\ Firouz Gahvari * \\ University of Illinois at Urbana-Champaign \\ Champaign, IL 61820, USA \\ January 1993, revised November 1995
}

${ }^{*}$ We thank Jacques Crémer and Jean-Jacques Laffont for helpful comments. The current version has benefitted substantially from the comments and advice of François Bourguignon and the referees. 


\begin{abstract}
This paper examines the role of public provision of goods as a redistributive mechanism when tax policies are designed optimally on the basis of the information available to the government. We characterize Pareto efficient allocations that are attainable through the tax policy, and derive the conditions under which public provision will enhance welfare above the maximum that can be achieved through a mix of a general income tax and commodity taxes (price subsidies). First, when there are two produced goods, we prove that public provision is always Pareto improving. This is achieved through changing individuals' actual consumption levels. Second, with no restrictions on the number of goods, we derive a sufficient condition for public provision to be Pareto improving. This is achieved by weakening self-selection constraints so that welfare improving tax changes are made possible. Suitable examples include provision of day care, basic health care and rights to a minimum old age pension.
\end{abstract}




\section{Introduction}

Until quite recently, there was a widely-held view among economists that cash dominates in-kind transfers. [See, for example, Aaron and Von Fürstenberg (1971)]. The view had its underpinning in the observation that while in-kind transfers constrain the behavior of their recipients, cash transfers do not. Guesnerie and Roberts (1984) classic paper successfully challenged this belief arguing that it made sense only in a first-best environment. They demonstrated that quantity constraints can indeed be Pareto improving in a second-best setting. ${ }^{1}$

The publication of Guesnerie and Roberts opened the way for other researchers to find justifications for in-kind transfers. Blackorby and Donaldson (1988) consider an economy consisting of two types of persons with only one type deriving utility from a publicly-provided good. First-best optima cannot be obtained due to lack of publicly available information on consumer types. This results in in-kind to generally Pareto dominate cash transfers. ${ }^{2}$ In Munro (1992), Boadway and Marchand (1995) and Gahvari (1995), first-best optima are ruled out because of the distortionary taxes that must be levied to finance the desired level of redistribution. This makes it possible to package in-kind transfers in such a way that they are welfare improving. ${ }^{3}$

In these models, the use of the tax system for redistributive purposes has either been

\footnotetext{
${ }^{1}$ There were earlier criticisms based on interdependent utilities. See, among others, Olsen (1971), and Daly and Giertz (1972).

${ }^{2}$ Nichols and Zeckhauser (1982) have a similar model where the two types differ in earning abilities and preferences. To receive transfers one has to report a low level of income where income is publicly observable. Preferences are such that, at a given income, intended recipients wish to consume more of the good than high-ability persons who misrepresent their type. Under this circumstance, providing too much transfers in kind make it less desirable for the high-ability to mimic the low-ability persons.

${ }^{3}$ In Gahvari, redistribution is carried out through a linear income tax and public provision. There are two types of persons in his model: the "rich" and the "poor". In-kind will then Pareto dominate cash transfers, if they are "over-provided" to the poor and if in-kind transfers and leisure are Hicks substitutes. Munro, on the other hand, restricts the set of tax instruments to linear income and commodity taxes. He proves that in-kind transfers are generally welfare improving if they are provided to consumers at a fixed charge. The paper by Boadway and Marchand, which came to our attention after our own paper was written, is somewhat closer to ours as they allow for a general income tax. However, they rule out commodity taxes. This has serious consequences for the results; see Section 6 below.
} 
totally ignored [as in Blackorby and Donaldson, and Nichols and Zeckhauser (1982)] or else subjected to arbitrary restrictions [as in Boadway and Marchand, Gahvari and Munro]. ${ }^{4}$ This paper examines the usefulness of public provision of goods as a redistributive instrument when tax policies are not artificially restricted and can be designed optimally, given the information available to the government. This is crucial. When the tax instruments are restricted, it is not at all obvious how one should interpret the usefulness of in-kind transfers. It maybe that they simply assume the role of the instruments left out. Put another way, one may be reintroducing (through the backdoor) an instrument that one has just ruled out.

The underlying informational structure is the one most commonly used in the optimal taxation literature. [See, for example, Edwards et al. (1993)]. Individuals' type (earning ability) and labor supply are not publicly observable; hence differential lumpsum taxes are not available and redistribution can be achieved only through distortionary taxation. ${ }^{5}$ On the other hand, individual incomes are observable so that nonlinear income taxes are feasible. ${ }^{6}$ Moreover, we assume that the tax administration has information on anonymous transactions but not on the identity of the consumers. That is, the administration observes the total sales of a commodity but not who bought how much. This is the standard assumption in the literature, so much so that it has been used as part of the very definition of indirect taxation. In discussing direct versus indirect taxation, Atkinson and Stiglitz (1980) write "the essential aspect of the distinction

\footnotetext{
${ }^{4}$ Yet another justification for in-kind transfers is provided by Besley and Coate (1991). They demonstrate that universal provision of certain goods (that induces only one group to participate in the public sector) can redistribute from the rich to the poor even if the transfers are financed by uniform lump-sum taxes. However, as they point out "this does not imply that such schemes will form part of a properly designed redistributional package" (p. 983).

${ }^{5}$ Uniform lump-sum taxes are feasible but they cannot achieve any redistribution, unless one resorts to public provision of the type Besley and Coate have considered.

${ }^{6}$ Earlier, Hylland and Zeckhauser (1979) had claimed that with the availability of a general tax on income only, redistribution should take place through taxation rather than in-kind transfers. In their model, however, in-kind transfers have no special role as preferences depend only on leisure and after tax income, with the benefits from in-kind transfers having the same effect on utility as an increase in income.
} 
[is] the fact that direct taxes may be adjusted to the individual characteristics of the taxpayer, whereas indirect taxes are levied on transactions irrespective of the circumstances of buyer or seller" (p. 427). This assumption precludes imposition of non-linear commodity taxes. However, linear commodity taxation is feasible. The required information for this type of taxation, particularly if it is levied on producers, is indeed public observability of anonymous transactions.

We model an economy consisting of two types of persons. The two types have identical preferences over produced goods and labor supply but differ in earning abilities. An individual's type and labor supply are not publicly observable, but his realized income is. The tax administration has information only on aggregate levels of transactions in the market, but not on quantities bought by each type. Given this information structure, we characterize Pareto efficient allocations that are attainable through tax policy (i.e. non-linear income and linear commodity taxes). To do this, we derive an optimal revelation mechanism. For our purpose, a mechanism consists not only of a set of typespecific before- and after-tax incomes, but also of a vector of commodity tax rates (same for everyone).

We identify two mechanisms via which in-kind transfers may enhance welfare above the maximum attainable through the available tax instruments. First, transfers can be provided at an amount which affects individuals' actual consumption levels. In a second-best environment, one may be able to set this in such a way as to increase tax revenues without reducing individuals' utility levels; that is, to effect Pareto improvements. We will prove that with two produced goods, this is always possible (provided that preferences are non-separable in labor and produced goods).

The second mechanism is through the weakening of self-selection constraints. When the maximum level of welfare attainable through taxation is constrained by self-selection, use of public provision can relax the constraints and allow further welfare improving tax changes. For the self-selection constraint to be eased, the government must set the 
minimum consumption constraint at a level which is greater than the desired consumption level of a high-wage person who misrepresents his type. In this way, mimicking the low-wage becomes less attractive to the high-wage person. We show that it may be possible to relax the self-selection constraint without affecting the actual consumption levels of either group. With no binding constraints on equilibrium consumption levels, the tax instruments can be adjusted to effect an unambiguous increase in welfare.

Finally, we identify the goods that their public provision is welfare enhancing to be complements to labor. This is the case because it is for these goods that it is possible to set the minimum consumption constraint at a level greater than the desired consumption level of a high-wage person who misrepresents his type (but less than what the low-wage person demands). Intuitively, since a "mimicker" works less to earn the income of a low-wage person, his demand for goods that are complements to labor will also be less. Suitable examples include provision of day care, basic health care and rights to a minimum old age pension.

\section{$2 \quad$ The setting}

Consider an economy consisting of two types of individuals: $N^{h}$ individuals of type $h$ and $N^{l}$ individuals of type $l$. They have identical preferences but differ in earning abilities. Individuals of type $l$ are less skilled and earn a lower wage than those of type $h$. The representative consumer in each group has preferences over labor supply, $L$, and $n$ produced goods, $\underline{x}=\left(x_{1}, x_{2}, \ldots, x_{n}\right)$. Producer prices are constant and set at one. Preferences are described by $U(\underline{x}, L)$ where $U$ is strictly quasi-concave and twice differentiable. An individual's type and labor input is not observable by the government; his before-tax income, $y=w L$, on the other hand is. It is then convenient to introduce a type-specific utility function, $u^{j}$, describing preferences over $x_{i}$ 's and $y$. It is defined by

$$
u^{j}(\underline{x}, y) \equiv U\left(\underline{x}, \frac{y}{w^{j}}\right) \quad j=l, h .
$$


where $w^{j}$ is the wage of an individual of type $j=l, h$ with $w^{h}>w^{l}$. Similar notation are used with other variables: superscripts $l$ and $h$ specify the value of a variable for individuals of the corresponding type.

\section{Publicly observable personal purchases}

Suppose that in addition to before-tax incomes, $y^{j}$ 's, the government could also observe personal purchases, $x_{i}^{j}$ 's. Tax structures will then be constrained by self-selection only. This is the model used by Stiglitz $(1982,1987)$ to discuss Pareto-efficient self-selection tax structures. While Stiglitz does not address the subject of in-kind transfers perse, his results on the usefulness of commodity taxation shed quite a bit of light on this issue. There are two related results. First, when preferences are weakly separable between labor supply and produced goods, Pareto efficient allocations (constrained by self-selection) can be implemented through a general income tax alone. Commodity taxes are not needed. Second, if preferences are not separable, Pareto efficient allocations can be implemented through a combination of a general income tax and commodity taxes. Together, these two results destroy any potential role for in-kind transfers.

It is important to point out that the required commodity taxes must (in general) be non-linear. This follows because Pareto efficiency in this context requires that the marginal rates of substitution between produced goods to differ across types. ${ }^{7}$ Linear commodity taxes cannot do the job as they would imply the same relative prices (for produced goods) for everyone. However, the non-linearity of commodity taxes pose no particular problem here. The assumption that $x_{i}^{j}$ 's are observable implies that the government will have no difficulty in levying non-linear taxes. Indeed, the tax imposed on a given commodity can even depend on the purchaser's consumption of other commodities as well as on his income.

\footnotetext{
${ }^{7}$ See expression (40b) in Stiglitz (1987, p. 1024). Note that Stiglitz does not explicitly address the issue of non-linear commodity taxes (except for strengthening his result in the case of separability).
} 
To sum up, there can be no role for in-kind transfers in this setting; any Pareto efficient self-selection allocation is readily implementable through the tax system. Of course, one may create a role for in-kind transfers by ruling out non-linear commodity taxation. However, this would be artificial. Given our observability assumption, there is no reason why in-kind transfers are feasible but non-linear commodity taxes are not. The foregoing discussion is summarized in the following proposition.

Proposition 1 If personal consumption levels are observable and if the government designs its tax policy in an optimal way, in-kind transfers are not welfare enhancing.

\section{Publicly observable anonymous transactions}

It is plain that information on personal consumption levels is not typically available to tax administrations, at least not for all commodities. What may reasonably be assumed available, is information on anonymous transactions (rather than on who purchased how much). Under this circumstance, non-linear commodity taxation is not feasible. It follows that we can no longer reject the usefulness of in-kind transfers on the basis of Proposition 1, even if the tax policy is optimally designed. The important question facing us is to determine if the type of information available to the government allows it to provide in-kind transfers that enhance welfare. This must be examined while ensuring that the tax policy itself is optimal, making use of all the available information.

Before proceeding any further, it is important to point out an implication of Stiglitz's $(1982,1987)$ results for the present setting. Recall our earlier argument in Section 3 that a (non-linear) income tax is sufficient to implement any Pareto efficient self-selection allocation if preferences are weakly separable in labor supply and produced goods. In that setting, we had assumed that the government has information on personal consumption levels. However, such type of information though available is of no use for the design of optimal taxes in this case. Consequently, with separability, in-kind transfers are not needed even if the information available is on anonymous transactions only. It 
follows that (assuming non-linear income taxation is feasible) in-kind transfers may be useful only if preferences are non-separable in labor supply and produced goods.

The assumption that the government observes only anonymous transactions implies that it lacks the required information to levy non-linear commodity taxes. As a rule, only linear commodity taxes are feasible. ${ }^{8}$ Note that the informational requirement for non-linear commodity taxation is much more stringent than for non-linear income taxation. The latter type of taxes require information only on each person's aggregate expenditure (or equivalently income). Non-linear commodity taxes, on the other hand, require information on each person's expenditure on every single good. ${ }^{9}$ The linearity of commodity taxes is thus not imposed as an ad-hoc restriction here; it is a direct implication of the informational structure. Given the available information, the government continues to optimize its tax policy and achieves a (constrained) Pareto efficient allocation. $^{10}$

We may now proceed to characterize Pareto efficient allocations that are constrained by both the standard self-selection constraint and the linearity of commodity taxes. To do this, we derive an optimal "revelation mechanism". For our purpose, a mechanism consists not only of a set of type-specific before-tax incomes, $y^{j}$ 's, and after-tax incomes, $c^{j}$ 's, but also of a vector of commodity tax rates (same for everyone). ${ }^{11}$ This procedure determines the commodity tax rates right from the outset. A complete solution to the optimal tax problem per-se then requires only the design of an implementing gen-

\footnotetext{
${ }^{8}$ For example, any attempt to tie-in commodity tax rates to the quantity purchased can easily be foiled by multiple purchases or asking others to make one's purchases.

${ }^{9}$ The type of information required for non-linear income taxation is typically assumed available in the optimum income tax literature.

${ }^{10}$ As in this paper, Boadway and Marchand assume that personal consumption levels are unobservable. However, they then go on to rule out commodity taxes altogether. As our earlier discussion indicates, it is difficult to justify this latter assumption on informational grounds. It also has serious implications for the results; see Sections 6 and 7 below.

${ }^{11}$ The combination of a general income tax with linear commodity taxes corresponds exactly to the setting considered by Atkinson and Stiglitz (1976) in their study of the design of optimal direct and indirect taxes. They solve the problem by using traditional methods as opposed to the mechanism design approach.
} 
eral income tax function. Note that instead of commodity taxes, the mechanism may equivalently specify the consumer prices, $\underline{p}=\left(p_{1}, p_{2}, \ldots, p_{n}\right)$.

To proceed further, it is necessary to consider the optimization problem of an individual for a given mechanism $(\underline{p}, c, y)$. This is necessitated by the fact that the mechanism determines personal consumption levels only indirectly, namely through prices. The mechanism assigns $\left(\underline{p}, c^{j}, y^{j}\right)$ to an individual who reports type $j$. The consumer then allocates his after-tax income $c^{j}$ between the produced commodities.

Formally, given any vector $(\underline{p}, c, y)$, an individual of type $j$ solves

$$
\begin{gathered}
\max _{\underline{x}} u^{j}(\underline{x}, y) \\
\text { subject to } \sum_{i=1}^{n} p_{i} x_{i}=c .
\end{gathered}
$$

The resulting demand functions are denoted by $x_{i}^{j}(\underline{p}, c, y)$ and the indirect utility function by

$$
v^{j}(\underline{p}, c, y) \equiv u^{j}\left(\underline{x}^{j}(\underline{p}, c, y), y\right) \text {. }
$$

Note that these functions are defined for a given value of $y$ and thus for a given level of labor supply (equal to $y / w^{j}$ ).

The characterization of Pareto efficient allocations may be simplified by assuming that at the optimum, only the incentive constraint of high-wage individuals is binding. That is, to achieve self-selection, the government must make sure only that high-wage individuals do not want to "imitate" the behavior of low-wage individuals. This is the "normal" case on which most of the literature has concentrated. Intuitively, it means that the tax policy involves redistribution from high- to low-wage individuals. ${ }^{12}$

\footnotetext{
${ }^{12}$ One must of course ensure that the "upward" incentive constraint is non-binding when the "downward" constraint binds. This is guaranteed if $c$ is a normal good. That is, if an individual does not reduce his aggregate expenditures on produced goods as a result of an increase in "exogenous income". Under this condition, one can easily show that a high-wage person's indifference curve through any point $(c, y)$ is flatter than that of a low-wage person.
} 
The government's problem can be written as

$$
\begin{aligned}
\max _{\underline{p}, c^{h}, y^{h}, c^{l}, y^{l}} v^{h}\left(\underline{p}, c^{h}, y^{h}\right)+\mu v^{l}\left(\underline{p}, c^{l}, y^{l}\right) \\
\text { subject to } \quad v^{h}\left(\underline{p}, c^{h}, y^{h}\right)-v^{h}\left(\underline{p}, c^{l}, y^{l}\right) \geq 0, \\
\qquad N^{h}\left[y^{h}-\sum_{i=1}^{n} x_{i}^{h}\left(\underline{p}, c^{h}, y^{h}\right)\right]+N^{l}\left[y^{l}-\sum_{i=1}^{n} x_{i}^{l}\left(\underline{p}, c^{l}, y^{l}\right)\right]-\bar{R} \geq 0,
\end{aligned}
$$

where $\bar{R}$ is the government's external revenue requirement and $\mu$ is a positive number.

Use a "hat" over variables to denote the solution to this problem and define

$$
\hat{x}_{i}^{j}=x_{i}^{j}\left(\underline{\hat{p}}, \hat{c}^{j}, \hat{y}^{j}\right)
$$

The Pareto efficient allocation is then given by $\underline{\hat{x}}^{h}, \hat{y}^{h}, \underline{\hat{x}}^{l}, \hat{y}^{l} .{ }^{13}$ It can be implemented by a linear commodity tax (at rates $\left.\hat{p}_{i}-1\right)$ together with a general income tax. The design of the implementing income tax function is straightforward. Once prices are fixed (at $\underline{\hat{p}}$ ), the problem collapses into a simple optimal general income tax problem (with just one composite commodity and labor supply) and the implementation can be achieved exactly as in Stiglitz (1987, p. 1002).

For future reference, we define

$$
\hat{x}_{i}^{h l}=\hat{x}_{i}^{h}\left(\underline{\hat{p}}, \hat{c}^{l}, \hat{y}^{l}\right),
$$

to denote the amount of good $i$ that an individual of type $h$ wishes to consume if he imitates a low-wage individual. Note that if personal purchases were observable (as in Section 3 ), $x_{i}^{h l}$ would be equal to $x_{i}^{l}$; otherwise, the individual would indeed be revealing his true type. With unobservable personal quantities, he can freely choose the quantities of the goods he consumes (but of course not his labor supply as before-tax income is observable). Corresponding to $\hat{x}_{i}^{h l}$ we also define

$$
\hat{v}^{h l}=u^{h}\left(\underline{\hat{x}}^{h}\left(\underline{\hat{p}}, \hat{c}^{l}, \hat{y}^{l}\right), \hat{y}^{l}\right)=v^{h}\left(\underline{\hat{p}}, \hat{c}^{l}, \hat{y}^{l}\right),
$$

\footnotetext{
${ }^{13}$ By "the solution" and "the Pareto-efficient allocation" we mean the solution conditional on the particular value of $\mu$.
} 
to denote the maximum utility attainable by an $h$ type who mimics an $l$ type person.

\section{Uniform public provision}

This section proves that using public provision as an additional policy tool to the mechanism $\left(\underline{\hat{p}}, \hat{c}^{h}, \hat{y}^{h}, \hat{c}^{l}, \hat{y}^{l}\right)$ of Section 4 , may improve welfare. We will consider public provision in its simplest form; that is when a uniform amount of a commodity is provided to everyone. ${ }^{14}$ The resale of the commodity is banned; however consumers are allowed to purchase extra quantities of the good at market prices if they wish. As Guesnerie and Roberts (1984) have noted, with resale in-kind will be equivalent to cash transfers. The policy then essentially amounts to imposing a minimum level of consumption for everybody. Of course, the feasibility of a resale ban will to some extent depend on the nature of the good which is subject to transfers in-kind. Consider provision of day care, basic health care, day care or a minimum old age pension. Due to the very nature of these services, it will not be too difficult to ensure that the intended recipients will not resell their allocations to others. ${ }^{15}$ Good $i$ is then said to be publicly provided in the following precise sense.

Definition 1 Uniform public provision of commodity $i$ at a level $\tilde{x}_{i}$ is the policy consisting of (i) providing each individual with $\tilde{x}_{i}$ units of good $i$, subject to its not being resold, and (ii) imposing a uniform lump-sum tax of $p_{i} \tilde{x}_{i}$ on all individuals.

With uniform public provision, the nature of individuals' optimization problem changes. Specifically, with public provision of (say) good 1, an individual of type $j$ solves the following problem given $(\underline{p}, c, y)$ and $\tilde{x}_{1}$

$$
\max _{\underline{x}} u^{j}(\underline{x}, y)
$$

\footnotetext{
${ }^{14}$ The question of the "optimal" type, and level, of public provision is not addressed in this paper.

${ }^{15}$ It is true that the nature of these goods may make them candidates for non-linear commodity taxation, or similarly non-uniform public provision, as well. However that may be, we are focusing here on uniform public provision and where people can top up their allocations. This would be particularly simple to implement.
} 


$$
\begin{array}{ll}
\text { subject to } & p_{1}\left(x_{1}-\tilde{x}_{1}\right)+\sum_{i=2}^{n} p_{i} x_{i}=c, \\
& x_{1} \geq \tilde{x}_{1} .
\end{array}
$$

\section{Public provision and actual consumption}

One possible route via which uniform public provision can affect welfare is through its impact on individuals' actual consumption levels. As demonstrated forcefully by Guesnerie and Roberts (1984), in a second-best environment, the government may be able to do this in such a way as to increase tax revenues without reducing individuals' utility levels. If this happens, welfare can be enhanced above the maximum attainable through the available tax instruments. This section proves that with two produced goods, this is always possible (provided that preferences are non-separable in labor and produced goods). ${ }^{16}$

Consider supplementing the mechanism $\left(\underline{\hat{p}}, \hat{c}^{h}, \hat{y}^{h}, \hat{c}^{l}, \hat{y}^{l}\right)$ with the uniform public provision of $x_{i}(i=1,2)$ at the level

$$
x_{i}^{*}=\min \left[\hat{x}_{i}^{h}, \hat{x}_{i}^{l}\right]+\epsilon, \quad i=1,2,
$$

where $\epsilon>0$ is sufficiently small such that $x_{i}^{*}<\max \left[\hat{x}_{i}^{h}, \hat{x}_{i}^{l}\right]$. There are three features of this policy which bear examination. First, for an infinitesimal $\epsilon$, this policy entails no change in the utility level of either type and hence aggregate welfare (as long as both persons find it best to tell the truth). This is obvious for person $k$ for whom $x_{i}^{*}$ is less than his original consumption level. As to the person whose consumption of $x_{i}$ increases by $\epsilon$, denote his utility level by $u^{j}$. We have

$$
\begin{aligned}
d u^{j} & =\frac{\partial u^{j}}{\partial x_{1}^{j}} d x_{1}^{j}+\frac{\partial u^{j}}{\partial x_{2}^{j}} d x_{2}^{j} \\
& =\frac{1}{p_{1}} \frac{\partial u^{j}}{\partial x_{1}^{j}}\left[p_{1} d x_{1}^{j}+p_{2} d x_{2}^{j}\right]=0 .
\end{aligned}
$$

\footnotetext{
${ }^{16} \mathrm{We}$ are grateful to a referee for pointing this out to us.
} 
Second, the self-selection constraint, $u^{h}\left(\underline{x}^{h}, y^{h}\right) \geq u^{h}\left(\underline{x}^{h l}, y^{l}\right)$ is not violated by uniform public provision. In the absence of transfers, this constraint binds at $\left(\underline{\hat{x}}^{h}, \hat{y}^{h}, \underline{\hat{x}}^{h l}, \hat{y}^{l}\right)$. Obviously, for the same before- and after-tax income, an increase in actual consumption of $x_{i}^{j}$ over $\hat{x}_{i}^{j}$ (whether $j=h$ or $l$ ) cannot make it more appealing for an $h$ to mimic an $l$ type. Hence the right-hand side of the self-selection constraint cannot increase from $\hat{v}^{h l}=u^{h}\left(\underline{\hat{x}}^{h l}, \hat{y}^{l}\right)$. As to the left-hand side, it was shown above that it will not be affected.

Third, from (4c), the impact of in-kind transfers on tax revenue,

$$
R=\sum_{j=l}^{h} N^{j}\left[y^{j}-c^{j}+\left(p_{1}-1\right) x_{1}^{j}+\left(p_{2}-1\right) x_{2}^{j}\right],
$$

may be found as follows. Given $\hat{y}^{j}$ and $\hat{c}^{j}$, an $\epsilon$ increase in consumption of $x_{1}^{j}(j=h, l)$ results in

$$
\begin{aligned}
d R & =N^{j}\left[\left(p_{1}-1\right) d x_{1}^{j}+\left(p_{2}-1\right) d x_{2}^{j}\right] \\
& =N^{j}\left[\left(p_{1}-1\right)+\left(p_{2}-1\right)\left(\frac{-p_{1}}{p_{2}}\right)\right] d x_{1}^{j} \\
& =N^{j} \epsilon \frac{p_{1}-p_{2}}{p_{2}} .
\end{aligned}
$$

In the same manner, an increase in $x_{2}^{j}$ would result in

$$
d R=N^{j} \epsilon \frac{p_{2}-p_{1}}{p_{1}} .
$$

Atkinson and Stiglitz (1976) have proved that when preferences are non-separable in labor supply and produced goods, ${ }^{17}$ optimal indirect taxes are non-uniform so that $p_{1} \neq p_{2}$. Consequently, tax revenue can be increased by either increasing $x_{1}^{j}$ or $x_{2}^{j}$.

Putting these three observations together, one can immediately deduce:

\footnotetext{
${ }^{17}$ Recall from our discussion in Section 4 that with separability, in-kind transfers are never useful.
} 
Proposition 2 With two produced goods, there always exists a Pareto-improving inkind transfer system (provided that preferences are non-separable in labor and produced goods). ${ }^{18}$

This result cannot be generalized to more than two goods; however. There will be no guarantee then that increasing consumption of one good will increase the tax revenue. The strong result is due to the lack of degrees of freedom in the model. Consequently, one has to look for another mechanism through which in-kind transfers can enhance welfare when there are more than two produced goods in the economy.

\section{Public provision and virtual consumption}

Quite independently of its impact on actual consumption levels, public provision may enhance welfare through another mechanism. This section proves that when optimal allocations satisfy self- selection constraints, public provision may be used to relax these constraints and to effect Pareto improving moves.

We begin by stating and proving a lemma which will facilitate the discussion of our main result here.

Lemma 1 Consider supplementing the mechanism $\left(\underline{\hat{p}}, \hat{c}^{h}, \hat{y}^{h}, \hat{c}^{l}, \hat{y}^{l}\right)$ by a policy of uniform public provision of good $i$. If the good is provided at the level $\tilde{x}_{i}=\min \left[\hat{x}_{i}^{h}, \hat{x}_{i}^{l}\right]-\epsilon$, with $\epsilon>0$ and sufficiently small to ensure $\tilde{x}_{i}>0$, it will not change individual demands and leaves the government's budget constraint unaffected.

\footnotetext{
${ }^{18}$ Boadway and Marchand (1995) consider an economy with two goods and allow for a general income tax only. Yet they identify a "necessary and sufficient" condition for in-kind transfers to be welfare improving (see their Proposition 1). Their result should be treated with great care. Without commodity taxes, it is indeed the case that equation (12) implies $d R=0$. However, this should not be interpreted to mean that in-kind transfers are not Pareto improving; only that we have not used all available instruments optimally. With two goods, given the structure of information in the economy, one can always improve welfare over the maximum obtainable through a general income tax only. No condition (necessary or sufficient) is required. Commodity taxes will increase welfare over and above a general income tax; uniform public provision will then enhance welfare even further.
} 
Proof: Without any loss of generality refer to the publicly provided good as good 1 . By definition $\underline{\hat{x}}$ solves the problem defined by $(2 \mathrm{a})-(2 \mathrm{~b})$. Under uniform public provision, after-tax incomes are given by $c^{j}=\hat{c}^{j}-\hat{p}_{1} \tilde{x}_{1}$ so that (8b) is equivalent to (2b). By the definition of $\tilde{x}_{1}, \hat{x}_{1}^{j}$ satisfies (8c); hence $\underline{\hat{x}}^{j}$ solves the problem defined by (8a)-(8c). This, together with $c^{j}=\hat{c}^{j}-\hat{p}_{1} \tilde{x}_{1}$, also implies that the government's budget constraint continues to be satisfied.

The public provision considered in Lemma 1 has no impact on individuals' equilibrium behavior. The minimum consumption constraint it imposes is not binding so that the solution remains interior for all individuals. This does not mean, however, that it has no impact on welfare. Indeed, we will show below that under some circumstances there will be an impact on welfare. This comes about as the constraint affects the set of feasible policies and thus the optimal solution to the government's problem. Roughly speaking, public provision of good $i$ at an "appropriate" level (provided that a certain relationship holds between the consumption levels of individuals when truthful and when not) will relax the self-selection constraint. This in turn opens up the door for various welfare improving changes in the tax system.

The last observation leads to the following condition which is crucial in determining if uniform public provision is welfare improving. ${ }^{19}$

Condition 1 The following inequality is satisfied for at least one of the commodities

$$
\hat{x}_{i}^{h l}<\min \left[\hat{x}_{i}^{h}, \hat{x}_{i}^{l}\right] .
$$

\footnotetext{
${ }^{19}$ The condition resembles that in Proposition 1 in Boadway and Marchand (1995). Note, however, that their set-up is very different from ours. Moreover, Condition 1 is imposed at the levels of demand at the second-best optimum corresponding to the mix of income and commodity taxes (which entails a higher level of welfare than that under an income tax only as in Boadway and Marchand). They also argue that their condition is both necessary and sufficient for welfare enhancing in-kind transfers. However, as our discussion in Section 6 shows, Condition 1 is irrelevant for the two-good case and not necessary for the general case. We will prove below that Condition 1 is in fact sufficient for the general case.
} 
Note that the condition is imposed on the levels of demand at the solution to the government's problem in (4a)-(4c). That is, it is imposed at the optimal allocation in the absence of in-kind transfers.

To gain an intuitive understanding of this condition, consider Figures 1 and 2 for a two good illustration. There are two possibilities in this case. ${ }^{20}$ First, $\hat{x}_{1}^{h}>\hat{x}_{1}^{l}$ and $\hat{x}_{2}^{h}>\hat{x}_{2}^{l}$ : high-wage individuals consume a larger amount of both commodities than low-wage individuals. ${ }^{21}$ This is depicted in Figure 1. By assumption $\left(\hat{x}_{1}^{l}, \hat{x}_{2}^{l}\right)$ lies to the south-west of $\left(\hat{x}_{1}^{h}, \hat{x}_{2}^{h}\right)$. Further, $\left(\hat{x}_{1}^{l}, \hat{x}_{2}^{l}\right)$ and $\left(\hat{x}_{1}^{h l}, \hat{x}_{2}^{h l}\right)$ are both on the budget line corresponding to $\hat{c}^{l}$. Given that $\hat{x}_{i}^{h l} \neq \hat{x}_{i}^{l}$ (which would generally be the case for nonseparable preferences), it is clear that Condition 1 must hold for one of the goods (good 1 in Figure 1). ${ }^{22}$

The second possibility is to have $\hat{x}_{1}^{h}<\hat{x}_{1}^{l}$ and $\hat{x}_{2}^{h}>\hat{x}_{2}^{l}$ (or the reverse): high-wage individuals consume a larger amount of one good but a smaller amount of the other one. Figure 2 depicts an example of such a situation [in which $\mathrm{A}$ is the point on the budget line corresponding to $\hat{c}^{l}$ located vertically below $\left.\left(\hat{x}_{1}^{h}, \hat{x}_{2}^{h}\right)\right]$. It is clear that in this case Condition 1 holds unless $\left(\hat{x}_{1}^{h l}, \hat{x}_{2}^{h l}\right)$ lies between point $A$ and $\left(\hat{x}_{1}^{l}, \hat{x}_{2}^{l}\right)$, that is unless $\hat{x}_{1}^{l} \geq \hat{x}_{1}^{h l} \geq \hat{x}_{1}^{h}$ and $\hat{x}_{2}^{l} \leq \hat{x}_{2}^{h l} \leq \hat{x}_{2}^{h}$. In words, the condition will be violated only if an $h$ type individual who pretends to be of type $l$ consumes an "intermediate" level of both goods. $^{23}$ [Figure 2 illustrates a situation where Condition 1 holds for good 1 . If $\left(\hat{x}_{1}^{h l}, \hat{x}_{2}^{h l}\right)$ were to the right of $\left(\hat{x}_{1}^{l}, \hat{x}_{2}^{l}\right)$, the condition would hold for good 2].

It is also instructive to note that Condition 1 is necessarily violated if the utility function is weakly separable between labor supply and produced goods. In that case

\footnotetext{
${ }^{20}$ Our results do not require $\hat{c}^{h}>\hat{c}^{l}$. While discussing Condition 1 we nevertheless neglect cases that would involve $\hat{c}^{l}>\hat{c}^{h}$. They are not very interesting as quite weak (and standard) assumptions on preferences would ensure $\hat{c}^{h}>\hat{c}^{l}$. A sufficient condition is that indifference curves over $(c, y)$ are steeper for low-wage individuals than for high-wage individuals; see for example Stiglitz (1987, p. 998).

${ }^{21}$ Note that with non-separable preferences normality of the two goods is not sufficient (nor necessary) to ensure that high-wage individuals consume larger quantities of both goods.

${ }^{22} \mathrm{As}\left(\hat{x}_{1}^{l}, \hat{x}_{2}^{l}\right)$ and $\left(\hat{x}_{1}^{h l}, \hat{x}_{2}^{h l}\right)$ satisfy the same budget constraint, one cannot have both $\hat{x}_{1}^{h l}>\hat{x}_{1}^{l}$ and $\hat{x}_{2}^{h l}>\hat{x}_{2}^{l}$. Hence we must have $\hat{x}_{i}^{h l}<\hat{x}_{i}^{l}<\hat{x}_{i}^{h}$ for one of the commodities so that Condition 1 holds.

${ }^{23}$ This being impossible in case 1 explains why the condition did always hold there.
} 

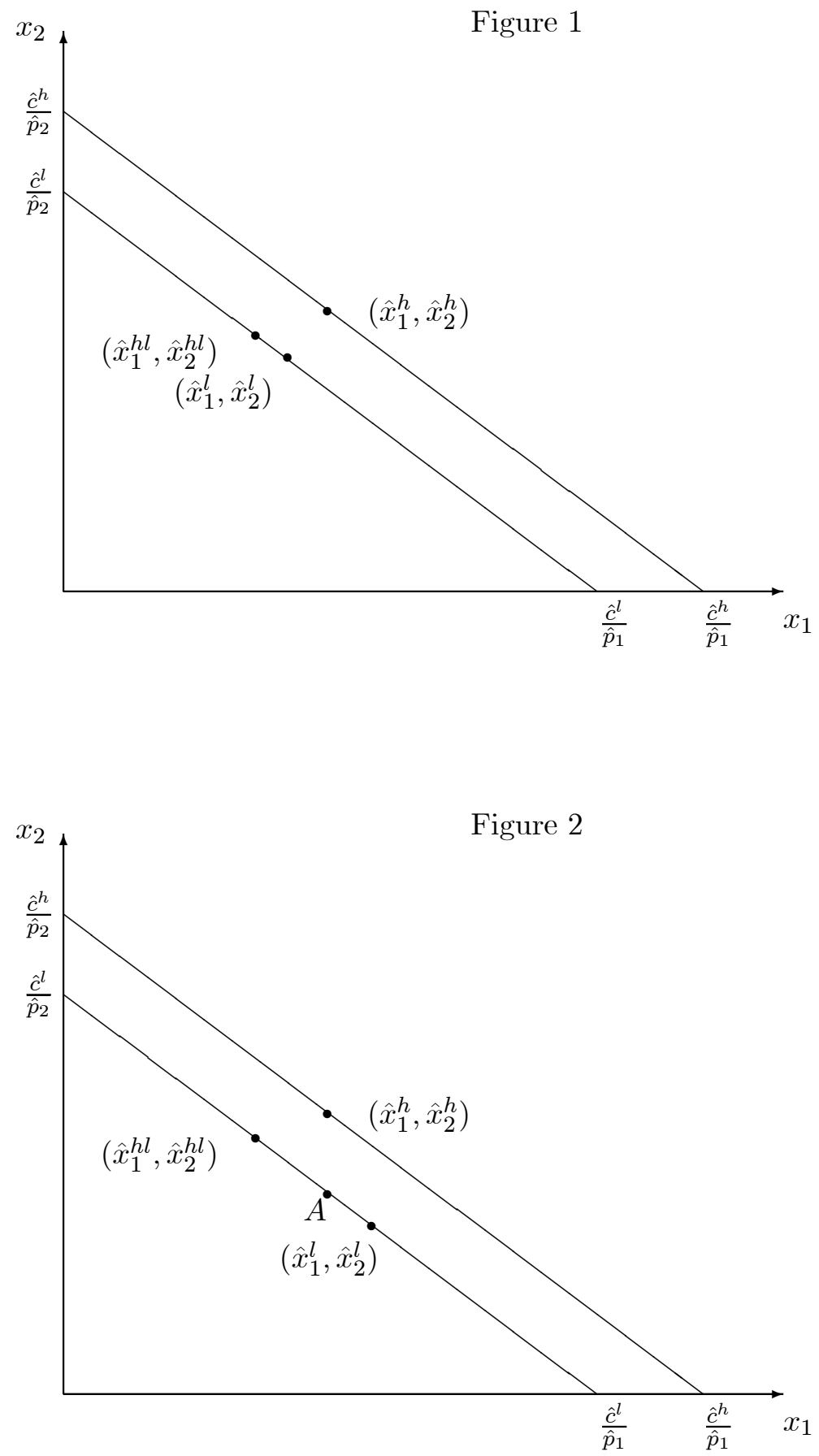
$\hat{x}_{i}^{h l}=\hat{x}_{i}^{l}$ for both goods. This follows because high-wage persons who pretend to be lowwage must have the same before-tax income as low-wage persons. Although this implies that high-wage individuals have a lower labor supply than the low-wage individuals, because of separability, both groups will necessarily have the same indifference curves over $\left(x_{1}, x_{2}\right)$. Now since they also have the same after-tax income $\left(\hat{c}^{l}\right)$ they will choose the same consumption bundles. Of course, the fact that Condition 1 is violated for separable preferences is of no consequence here. Section 4 has already established that in this case in-kind transfers can never be welfare improving.

The foregoing discussion sheds light on the nature of commodities which satisfy Condition 1. Consider a high-wage who misrepresents his type. He will earn the low-wage person's income but will work less. The two have, by assumption, identical preferences. Consequently, the mimicker's marginal rate of substitution between any two goods $x_{i}$ and $x_{f}$ differs from the low-wage individual's marginal rate of substitution (at the latter's desired consumption level) essentially because of their different labor supply. The mimicker's lower labor supply results in his having a lower marginal rate of substitution between $x_{i}$ and $x_{f}$, and thus a lower demand for $x_{i}$, if $x_{i}$ is complementary to labor. This is indeed what Condition 1 requires. Consequently, the goods which are complements to labor are the prime candidates for public provision. It is interesting to note that our earlier examples of health care and a minimum old age pension, which required no added information to enforce a ban on their resale, also satisfy the complementarity requirement.

For ease of reference from now on we shall assume that goods are indexed in such a way that whenever Condition 1 is satisfied, inequality (13) holds for good 1 . We are in a position to state our main result.

Proposition 3 Assume that Condition 1 holds. Then, the government can improve welfare over the mechanism $\left(\underline{\hat{p}}, \hat{c}^{h}, \hat{y}^{h}, \hat{c}^{l}, \hat{y}^{l}\right)$ by introducing uniform public provision of good 1 at the level $\tilde{x}_{1} \equiv \min \left[\hat{x}_{1}^{h}, \hat{x}_{1}^{l}\right]-\epsilon$, with $\epsilon>0$ and sufficiently small to ensure 
$\tilde{x}_{1}>\hat{x}_{1}^{h l}$, while adjusting the tax policy.

Proof: From Lemma 1, it follows that if the government appends in-kind transfers to the original mechanism $\left(\underline{\hat{p}}, \hat{c}^{h}, \hat{y}^{h}, \hat{c}^{l}, \hat{y}^{l}\right)$, both individuals will continue to consume the same bundles as previously while the government's budget constraint remains in balance. However, as we will show below, the self-selection constraint (4b) will no longer bind at this allocation. Consequently, the government will be able to adjust its tax policy and improve welfare.

In the absence of transfers, an $h$ type person will attain $v^{h}\left(\underline{\hat{p}}, \hat{c}^{h}, \hat{y}^{h}\right)$ if he tells the truth and $\hat{v}^{h l}$ if he cheats. Moreover, with the self-selection constraint (4b) being binding, we have

$$
v^{h}\left(\underline{\hat{p}}, \hat{c}^{h}, \hat{y}^{h}\right)=\hat{v}^{h l} .
$$

With transfers of $\tilde{x}_{1}>\hat{x}_{1}^{h l}$, Lemma 1 implies that this person's utility will continue to be $v^{h}\left(\underline{\hat{p}}, \hat{c}^{h}, \hat{y}^{h}\right)$ if he is truthful. On the other hand, if he were to cheat $\hat{x}_{1}^{h l}$ [his unrestricted choice of $x$ when facing $\left.\left(\underline{\hat{p}}, \hat{c}^{l}, \hat{y}^{l}\right)\right]$ will no longer be feasible under uniform public provision. It follows that the maximum utility he can attain by cheating, $\tilde{v}^{h l}$, cannot be as high as previously. Thus,

$$
\tilde{v}^{h l}<\hat{v}^{h l} .
$$

This inequality in conjunction with equation (14) then implies that

$$
\tilde{v}^{h l}<v^{h}\left(\underline{\hat{p}}, \hat{c}^{h}, \hat{y}^{h}\right) .
$$

Proposition 3 proves that in-kind transfers can indeed be welfare enhancing. The following comments help develop an intuitive understanding for the proposition. First, the welfare improvement is achieved through a combination of two policies: uniform public provision is used concomitantly with an adjustment in the tax policy. The welfare improvement results from the adjustments in tax policy rather than from public 
provision per se. However, the changes in tax policy are feasible only because of public provision. By definition, if public provision were not used, any welfare improving tax change from the solution to the government's optimization problem in Section 4 must violate the self-selection constraint. The role of public provision is to relax the self-selection constraint so that welfare improving tax changes are made possible.

Second, public provision in effect imposes a minimum consumption constraint (for one of the commodities) on all individuals. However, this constraint is not binding at the actual consumption levels. It is perceived as binding only by high-wage individuals who evaluate the benefits of misrepresenting their type. In this case, their consumption level would be given by a corner solution. But this is a purely hypothetical consumption level as nobody misrepresents his type at the self-selection equilibrium.

Third, it has been shown above that the informational structure imposes linearity on the commodity tax schedule. One may then wonder if the source of the welfare improvement is not some form of non-linearity in the commodity tax structure created by public provision. Our previous remark shows this is not the case. In spite of the public provision everyone continues to choose his consumption bundle at an interior solution. Marginal rates of substitution (between produced commodities) are thus equalized across groups and the commodity tax remains linear.

Fourth, since a mimicker works less to earn the income of a low-wage person, his demand for goods that are complements to labor will also be less. The complementarity property thus allows the government to set the minimum consumption constraint at a level which makes the low-wage person's package less appealing to the high-wage person without reducing its utility to the low-wage persons themselves. In turn, this allows further welfare improving redistribution to take place.

Fifth, the inclusion of $\epsilon$ in Proposition 3 implies that public provision is set at a level which is lower than the smallest actual consumption level. One may wonder why the good is not simply provided at the level $\min \left[\hat{x}_{i}^{h}, \hat{x}_{i}^{l}\right]$. As a matter of fact, in most sit- 
uations our results would remain valid with this alternative level of public provision. ${ }^{24}$ However, if the publicly provided good is an inferior good, some complications may arise. Suppose the good is provided at the level $\hat{x}_{i}^{l}$. The public provision in itself will not change the low-wage individuals' behavior: they receive what they want to consume. However, the accompanying change in tax policy increases their disposable income enticing them to reduce their consumption of the inferior good. But the minimum consumption constraint prevents them from doing this. The increase in their utility will thus be lower with than without the constraint. It may not even be large enough to outweigh the decrease in the utility of high-wage individuals.

Finally, before concluding this section, we must comment on how Proposition 3 may be generalized to economies with more than two consumer types. The key requirement is the weakening of an otherwise binding incentive compatibility constraint through public provision. A variant of Condition 1 provides a sufficient condition. Assume there are $m$ types of consumers, and consider all binding self-selection constraints corresponding to a $k$ type person mimicking an $s$ type $(k$ and $s=1,2, \ldots, m) .{ }^{25}$ The required condition is for the inequality $\hat{x}_{i}^{k s}<\min _{j}\left[\hat{x}_{i}^{j}\right]$ to hold for at least one of the goods $i=1,2, \ldots, n$, for one (or more) of $(k, s)$ pairs. [The "hat" notation is as in the two person case].

\section{Concluding remarks}

Governments typically effect redistribution through a variety of means: public provision as well as the tax system. This paper has examined the conditions under which public provision is a useful redistributive tool to complement an optimally designed tax policy - a general income tax plus commodity taxes (price subsidies). The important lesson that has emerged is that public provision can affect welfare through two distinct mechanisms. First, it can change individuals' actual consumption levels. And, in

\footnotetext{
${ }^{24}$ The formal proofs are more complicated though.

${ }^{25}$ One would expect that the incentive constraint to bind for a $k$ type who mimics a $(k-1)$ type. However, this is not guaranteed as with more than two types one may have bunching.
} 
a second-best environment, the change can be Pareto improving. Furthermore, when there are two produced goods, this is always feasible.

The second mechanism is through the weakening of self-selection constraints. When optimal allocations satisfy self-selection constraints, public provision may be used to relax these constraints. This allows the tax system to be utilized further to get the economy "closer" to full information Pareto-efficient allocations. This particular way of looking at in-kind transfers is different from the first mechanism and what has generally been emphasized in the literature. Previously, the role of in-kind transfers had been seen in their boosting up the supply of labor thus advocating public provision of goods which are complements to labor. While our study also favors provision of goods that are complementary to labor, it is not for the purpose of boosting the labor supply. Its aim is strictly to make the low-wage individuals' package less appealing to high wage individuals. While we identify certain goods that are good candidates for public provision, it is clear that we need to learn more about the role of in-kind transfers in order to deduce what should or should not be provided publicly.

A related question that must be studied is the question of the characterization of the "optimal policy" with public provision (as opposed to proving that public provision is useful). This is an important undertaking which may help identify the range of goods that should be provided publicly. We leave these questions for further research. 


\section{References}

Aaron, H.J. and G.M. Von Fürstenberg (1971) "The inefficiency of transfers in kind: the case of housing assistance," Western Economic Journal, 9, 184-191.

Atkinson, A.B. and J.E. Stiglitz (1976) "The design of tax structure: direct versus indirect taxation," Journal of Public Economics, 6, 55-75.

Atkinson, A.B. and J.E. Stiglitz (1980) Lectures on Public Economics. New-York: McGraw-Hill.

Besley, T. and S. Coate (1991) "Public provision of private goods and the redistribution of income," American Economic Review, 81, 979-984.

Blackorby, C. and D. Donaldson (1988) "Cash versus kind, self-selection, and efficient transfers," American Economic Review, 78, 691-700.

Boadway, R. and M. Marchand (1995) "The use of public expenditures for redistributive purposes," Oxford Economic Papers, 47, 45-59.

Daly, G. and F. Giertz (1972) "Welfare economics and welfare reform," American Economic Review, 62, 131-138.

Edwards, J., M. Keen and M. Tuomala (1993) "Pareto efficiency, mixed taxation and the provision of public goods," mimeo.

Gahvari, F. (1995) "In-kind versus cash transfers in presence of distortionary taxes," Economic Inquiry, 33, 45-53.

Guesnerie, R. and K. Roberts (1984) "Effective policy tools and quantity controls," Econometrica, 52, 59-86.

Hylland, A. and R. Zeckhauser (1979) "Distributional objectives should affect taxes but not program choice or design," Scandinavian Journal of Economics, 81, 264-284.

Munro, A. (1992) "Self-selection and optimal in-kind transfers," Economic Journal, 102, $1184-1196$.

Nichols, A.L. and R.J. Zeckhauser (1982) "Targeting transfers through restrictions on recipients," American Economic Review (Papers and Proceedings), 72, 301-317.

Olsen, E.O. (1971) "Subsidizing housing in a competitive market: Reply," American Economic Review, 61, 220-224.

Stiglitz, J.E. (1982) "Self-selection and Pareto efficient taxation," Journal of Public Economics, 17, 213-240.

Stiglitz, J.E. (1987) "Pareto efficient and optimal taxation and the new new welfare economics," in Handbook of Public Economics, Vol 2, ed. Auerbach, A. and M. Feldstein. Amsterdam: North-Holland, 991-1042. 
Page: 1

2 The setting

1

se:model

eq: def.uj

Page: $\quad 4$

Page: $\quad 4$

3 Publicly observable personal purchases

$$
\begin{aligned}
& \text { se:stiglitz } \\
& \text { pr:nouse }
\end{aligned}
$$

Page: $\quad 5$

Page: $\quad 6$

4 Publicly observable anonymous transactions

se:main
eq:ind.probl.obj
eq:ind.prob.constr
eq:ind.ut
eq:pr 2. obj
eq:pr 2. ic
eq:pr $2 \cdot$ gbc
eq:def.bx
eq:def.xhl
eq: def.vhl

5 Uniform public provision

$$
\begin{aligned}
& \text { se:upp } \\
& \text { de:public } \\
& \text { eq:ind.probl.upp.obj } \\
& \text { eq:ind.prob.upp.constr1 } \\
& \text { eq:ind.prob.upp.constr2 } \\
& \text { actual consumption } \\
& \text { se: } 2 \text { good } \\
& \text { eq:actual } \\
& \text { eq: } \operatorname{tr} \\
& \text { eq:dr1 } \\
& \text { eq:dr2 } \\
& \text { pr: } 2 \text { good }
\end{aligned}
$$$$
\text { eq: ind.prob.upp. constr } 1
$$

6 Public provision and actual consumption

Page: $\quad 6$

Page: 8

Page: $\quad 8$

Page: $\quad 8$

Page: $\quad 9$

Page: 9

Page: 9

Page: $\quad 9$

Page: 9

Page: 9

10

Page: 10

Page: $\quad 10$

$\begin{array}{lll}8 \mathrm{a} & \text { Page: } & 10 \\ 8 \mathrm{~b} & \text { Page: } & 11\end{array}$

8c Page: 11

virtual consumption

Page: 13

Page: 13

Page: 14

Page: 14

Page: 17

Page: 18

Page: 18 
eq:vjtilde1

8 Concluding remarks

se: conclus
16 Page: 18

$8 \quad$ Page: 20

20 